\title{
Ensinar Pierre Bourdieu no 9-3: o que falar quer dizer
}

Fabien Truong ${ }^{2}$

\section{Resumo}

Este artigo aborda o confronto entre a alta teoria social de Bourdieu e um público desarmado para apropriar-se de sua visão sobre a dominação simbólica e a desigualdade social: os alunos imigrantes de classe baixa de escolas secundárias localizadas na periferia urbana em declínio da Grande Paris. Através de um intenso trabalho de campo sociológico, proponho uma observação empírica da recepção social da obra de Bourdieu. Questiona o risco de comportamentos sem sentido para alunos e professores, já que a teoria de Bourdieu está indo contra o grão meritocrático necessário na sala de aula e explora o significado subjetivo da teoria da dominação para indivíduos dominados, entre aceitação e negação. Este estudo mostra que, nos banlieues franceses é criado um sentimento individual e precário de autoempoderamento.

Palavras-chave: Bourdieu. Reprodução. Meritocracia. Determinismo. Desigualdade.

\section{Introdução}

Eu gostaria de testemunhar aqui uma intrigante experiência social e educacional, embora atual, porque institucionalizada e consagrada pelos programas oficiais, ou seja, o ensino da teoria da dominação e da reprodução

I Este artigo foi publicado originalmente sob o título "Enseigner Pierre Bourdieu dans le 9-3: ce que parler veut dire", na Revue Socio-Logos, n. 5, 20 I0, disponivel em: https://journals.openedition.org/socio-logos/2446\#bodyftn I2 (TRUONG, 2010). Agradecemos ao autor Fabien Truong e aos editores da revista pela graciosa autorização, pela confiança na tradução e publicação do texto. Tradução de Amurabi Oliveira, professor da Universidade Federal de Santa Catarina, Pesquisador do CNPq.

2 Doutor em Sociologia pela Escola de Altos Estudos em Ciências Sociais (França), Professor do Departamento de Sociologia e Antropologia da Universidade de Paris 8. É atualmente o responsável pelo mestrado MEEF SES (Sciences de l'éducation et de la formation - Sciences économiques et sociales), que é uma preparação para o concursos para certificação de professor do ensino secundário na França na área de Ciências Econômicas e Sociais. Commons. Com essa licença você pode compartilhar, adaptar, para qualquer fim, desde que atribua a autoria da obra, forneça um link para a licença, e indicar se foram feitas alterações. 
de Pierre Bourdieu para os alunos da série Educação Secundária (ES) no "distrito 93" . Eu de fato ensinei Ciências Econômicas e Sociais (CES) lá de 2004 a 2010, em quatro diferentes escolas secundárias, minha condição de TZR 4 na área de reposição de "Bobigny"s levou-me a trabalhar em um novo estabelecimento praticamente todos os anos.

Ao mesmo tempo, o momento "Pierre Bourdieu" foi um ponto alto no ano, um momento de questionamento coletivo, para a turma e para o professor, e uma virada particularmente delicada para negociar.

\section{Alunos do ensino médio no 93}

Vamos começar descrevendo brevemente o perfil dos alunos do ensino médio no departamento. Estes são estudantes que estão claramente situados na parte inferior da hierarquia social. São conhecidos os dados relativos ao desemprego ${ }^{6}$, os beneficiários de políticas sociais de renda mínima ${ }^{7}$, os rendimentos $^{8}$ e a distribuição das categorias socioprofissionais (CSP) do departamento. A inspeção acadêmica constata em seu site que $50 \%$ da população de estudantes universitários em 2006 veio de uma CSP9 "desfavorecida" (que coloca o departamento na $4^{\text {a }}$ posição entre os 12 departamentos mais populosos do país).

Esses estudantes conseguem em média não ir tão bem no seu percurso de escolaridade quanto os demais alunos do país: em 2008, 74,3\% dos

30 distrito 93 refere-se à classificação organizativa da educação na França de acordo com a Direção de Serviços Departamentais da Educação Nacional. Nota do Tradutor (NT)

4 Titulaires sur Zone de Remplacement (TZR) é um professor titular do ensino secundário francês, designado definitivamente em uma zona de substituição. Esta tarefa é relativamente comum e, na maioria das vezes, reflete a entrada na carreira.

5 Bobigny é uma comuna francesa do departamento de Seine-Saint-Denis, região da Ilha de França. NT.

6 Uma taxa de desemprego de 9,4\% no primeiro trimestre de 2008 contra 7,2\% para toda a França metropolitana segundo o Instituto Nacional de Estatística e Estudos Econômicos (INEEE).

7 O número de beneficiários do Renda Mínima de Inserção (RMI) permanece bem acima da média francesa (em 3 I de dezembro de 2008, é o departamento que atinge a maior taxa com 64 pessoas a cada 1.000 habitantes como beneficiários do RMI, contra 3 I por 1.000 na região administrativa de Ilha de França, de acordo com o INEEE)

8 Uma média salarial de 12 euros por hora para todos os funcionários em tempo integral, em comparação com 16 euros para todos os funcionários em tempo integral na França, de acordo com o INEEE.

$97,1 \%$ de quadros e profissões intelectuais superiores contra 15,2\% dos trabalhadores, e 21,8\% dos funcionários em 2006 de acordo com o INEEE. 
alunos do último da ES do distrito 93 concluíram o Baccalauréat ${ }^{10}$ (bac) contra $85,4 \%$ de toda a França ${ }^{11}$. Assim, afora uma única escola secundária, todas as instituiçóes onde trabalhei foram classificadas como atribuição de prioridade para melhoria APV ${ }^{1213}$. Devemos também assistir à publicação dos resultados do bac em uma escola secundária em Seine Saint-Denis para medir o que ela representa para esses alunos. Lágrimas, gritos de alegria, nenhuma dança, agradecimentos infinitos e intermináveis dirigidos aos professores são todas manifestaçóes do valor dado ao diploma, que é muito mais percebido como resultado e um fim em si do que como uma passagem e um passaporte para o ensino superior, como é o caso em outros departamentos. A obtenção do bac é um passo excepcional que distingue o bem-sucedido do seu ambiente doméstico. Outra indicação seria entender o símbolo de distinção representado pelo bac para esses alunos: de acordo com minhas observaçóes, nas diferentes escolas secundárias onde lecionei, entre um terço e um quarto dos alunos da segunda série que tive em sala de aula foram reorientados no final do ano, deixando assim a educação geral e tecnológica. Além disso, durante as reunióes com a família, os pais muitas vezes expressam o desejo de que seu filho receba um diploma que eles não possuem.

Finalmente, a grande maioria deles são filhos de imigrantes ou estrangeiros. Os números da imigração do departamento estão aqui mais uma vez conhecidos. Mas o que parece ainda mais revelador do que a questáo da nacionalidade é a dimensão "étnica” dos estudantes do ensino médio na região, o que parece evidente para aqueles que ensinam no departamento, tanto que ele é onipresente, mas que é em grande parte invisível ao olho

10 É um diploma nacional referente ao final dos estudos secundários, que podem ser gerais, tecnológicos ou profissionais. O ensino de CES ocorre nos liceus na orientação econômica e social, havendo ainda a orientação literária e científica. NT.

11 Estes resultados mais fracos também são observáveis para todos os graus de bac: $78,8 \%$ contra $89 \%$ para o bac geral, $68,4 \%$ contra $78,8 \%$ para o bac profissional e $71,2 \%$ contra $81,8 \%$ para o bac tecnológico em 2008, segundo dados do Ministério da Educação Nacional.

12 Affectation à caractère Prioritaire justifiant une Valorisation (APV) referem-se a áreas criadas em 1981 pelo sistema educativo Francês às quais são destinados maiores recursos, considerando as dificuldades sociais $e$ escolares existentes.

13 Quanto à única escola secundária não-APV, ela atendeu aos critérios de classificação; mas, o diretor recusouse a classificá-la, mostrando uma vontade explícita de não discriminar seu estabelecimento. 
externo, em particular, dada a ausência de estatísticas “étnicas” na França. De minha parte, de todas as aulas em que lecionei durante seis anos, vejo que 91\% dos meus alunos têm um nome com sonoridade do Norte da África, Africano, Asiático, Português, Espanhol ou do Leste Europeu e que $9 \%$ ostenta um nome de sonoridade "francês"14 (calculado em um painel de 312 alunos). Os alunos referem-se muitas vezes à sua origem étnica e expressam muito claramente a estranheza da sua condição em relação ao modelo abstrato e universal do estudante do ensino secundário ao qual deve se dirigir a escola da República. Eles regularmente traduzem essa estranheza na ideia de que "não somos os mesmos", testemunhando implicitamente a falta de legitimidade dentro da instituição escolar e mais amplamente dentro da sociedade (SAYAD, 2006). O que torna necessário pensar também a questão social em sua articulação com o que parece ser também a "questão racial" (FASSIN; FASSIN, 2009).

\section{O que fazer?}

Assim, os estudantes que estão diante de mim são objetivamente, no sentido de Bourdieu, estudantes que são dominados socialmente, economicamente, culturalmente e academicamente. Não só será necessário falar sobre essa dominação, mostrá-la e demonstrá-la, mas também será necessário indicar de que maneira o papel desempenhado pela escola e pelo professor apenas acentua as desigualdades estruturais. Esta é obviamente uma posição desconfortável e insustentável para o professor. $\mathrm{O}$ único discurso possível no cotidiano é de fato o discurso meritocrático, porque é o único que pode fazer sentido para o professor e para os alunos. Se eu começar a pensar que minhas aulas são inúteis e que meus alunos estão fadados ao fracasso, não estou mais ensinando. Se os alunos acharem que tudo já está dado, eles não se empenham mais.

A sociologia de Bourdieu, portanto, coloca um problema fundamental que teremos que resolver como uma classe: a do significado de nossa ação.

Ele também coloca uma questão muito concreta para o professor: como expor sua tese sem desencadear hostilidade ou desprezo, que seriam

14 O que corresponde, no meu cálculo estatístico, aos restantes nomes, isto é, aos nomes que não têm consonância norte-africana, africana, asiática, portuguesa, espanhola ou do Leste Europeu. 
as duas faces de uma reação esperada à expressão da "violência simbólica" latente no discurso a vir e a seguir.

\section{Aceitação e identificação}

A primeira reação de meus alunos - e essa constataçấo foi confirmada a cada vez - é a aceitação implícita e imediata do discurso sobre dominaçáo. Este primeiro momento de concordância e aquiescência geral sempre se desdobrou em um segundo momento de identificação quase automática com a classe dos "dominados". Este duplo movimento é particularmente visível nas reaçóes a uma sequência que apresento no primeiro ano (capítulo sobre socialização e cultura) e no ano final da ES (capítulo sobre a estrutura social) e que consiste em trabalhar sobre um texto que define a oposição entre "alimentação popular francesa" e o modelo alimentar burguês (BOURDIEU, 1979). Este texto corresponde, além disso, à primeira introdução aos escritos de Pierre Bourdieu para os dois níveis:

Ele está certo, senhor, uma boa refeição, é um cuscuz ou um kebab. Não ficamos com fome depois. (Fedh, Primeiro ano da ES).

Não é lógico. Os burgueses ainda estão com fome depois da refeição, enquanto nós não! (Risada geral) (Gabriel, Primeiro ano da ES).

Isso é muito de nós! Pare, senhor, seu texto me deu fome. E é quase meio-dia! (Mounirou, Último ano da ES).

Aqui podemos ver dois elementos significativos. Primeiro, a grande internalização do modelo dominante/dominado pelos estudantes que estão muito rapidamente, e de forma explícita, no grupo dos dominados - o que é indicado pelo uso de sua reação oral à dicotomia "Eles"/"Nós", que é próprio da cultura de classe popular como bem mostrou Richard Hoggart (1970). Então, um forte sentimento de simpatia em relação a Pierre Bourdieu, que parece descrever "seu mundo" e "suas" práticas.

\section{A negação impossível}

Essa primeira reação contrasta com a reação dos alunos quando nos movemos para a sequência sobre a escola. Isso consiste em apresentar a desigualdade do sucesso educacional de acordo com o CSP de origem usando 
tabelas estatísticas do INEEE, um trecho do texto de Bourdieu (1964) sobre capital cultural e, finalmente, de uma apresentação do tipo magistral sobre a teoria dos capitais. Talvez porque o assunto comporte mais questóes diretas para os alunos do que beber e comer, é muito mais questionado e criticado pelos alunos.

Senhor, isso foi há muito tempo. Foi na sua época! (Khalifa, Último ano da ES).

Ele está errado. Não é mais assim agora na escola. Em todo caso, eu não penso assim. (Sihem, Último ano da ES).

Isso é um abuso, senhor. Ele exagera. Parece que ele vê o mal em todos os lugares. (Zohair, Último ano da ES).

Contudo, essa fase de negação não pode durar muito, porque as objeçôes históricas ou morais dos alunos não levam em conta os mais recentes documentos estatísticos do INEEE, especialmente aqueles que estabelecem uma correlação estatística entre o nível de estudo do filho e CSP do pai. As oposiçóes sociológicas à teoria de Bourdieu proposta pelo programa também não reforçarão essa posição de negação temporária, uma vez que elas se relacionam principalmente a consideraçóes epistemológicas - por exemplo, a tese de Raymond Boudon (1973) que não questiona o que causa os postos problemas aos alunos: a constatação de um fracasso socialmente construído. Segue-se, então, uma reação geral que oscila entre a consciência de alguns e o fatalismo de outros.

Está ruim pra gente, senhor! (Tahar, Último ano da ES).

Basicamente, não temos realmente uma escolha em nossos estudos, senhor? (Will, Último ano da ES).

É deprimente a sociologia! (Josshua, Último ano da ES).

É neste momento que o professor deve encontrar uma porta de saída para os alunos. Se o capital de simpatia que Bourdieu até então acumulou parece ter desaparecido completamente, o essencial não está lá: a maioria dos alunos faz uma leitura pessoal das descobertas sobre o sucesso desigual na escola apresentado em sala de aula e projeta suas dificuldades em um jogo de espelho um pouco em sua vantagem. 
Basicamente, estamos ferrados, senhor! (Sékou, Último ano da ES).

Isso significa que não podemos fazer isso? (Fatiha, Último ano da ES).

Esta leitura personalizada do trabalho do sociólogo se projeta de maneira muito frequente sobre o professor. Em geral é neste momento que as questôes pessoais são colocadas para mim:

E você, senhor, você vem de qual classe social? O que seus pais fizeram? (Iklhef, Último ano da ES).

Os estudantes também são muito mais prementes quando eu apresento o papel inconsciente desempenhado pelo professor no mecanismo de reprodução, porque insiste na distância social e cultural entre o professor e os alunos das categorias populares e na homologia do habitus entre este e os alunos provenientes das categorias superiores. Essa distância é muitas vezes mal interpretada pelos alunos, que a equiparam a um complexo de superioridade.

Como você se sente em relação a nós, senhor? (Mounirou, Último ano da ES).

Isso significa que você é burguês então? (Josué, Último ano da ES).

Estou tentando afastar o debate de sua dimensão pessoal e emocional, oferecendo aos alunos duas interpretaçóes morais e práticas do que acaba de ser dito e que nos permitirá superar a situação de impasse na qual arriscamos encontrarmo-nos.

\section{As virtudes do determinismo}

A primeira resposta de ordem moral e filosófica é a que foi abordada pelo próprio Bourdieu quando ele foi acusado de ter uma teoria mecanicista, por meio da qual os indivíduos são privados de liberdade de ação e de capacidade de iniciativa. $\mathrm{O}$ conhecimento sociológico é o primeiro passo para a liberdade: é conhecendo seus determinismos que se pode ser verdadeiramente livre. Aqui encontramos a leitura social que faz Bourdieu do conceito de liberdade de Espinosa ([1677] 1965) ${ }^{15}$.

15 Espinosa, portanto, critica a noção de "liure-arbítrio" em sua Éthica: "Os homens pensam que são liures pelo simples fato de estarem conscientes de suas ações e ignorantes das causas pelas quais são determinados" (ESPINOSA, [1677] 1965, p. 139). 
Citemos aqui Pierre Bourdieu (1980, p. 41): “A sociologia [...] oferece um meio, talvez o único, de contribuir, nem que seja pela consciência das determinaçóes, à construção, que de outro modo poderia ser abandonada às forças do mundo, de algo como um sujeito". Também podemos encontrar essa concepção na sequência em que Bourdieu tem que enfrentar as críticas dos jovens de Val Fourré durante um debate em que se sentem desarmados e agredidos pelo discurso do sociólogo no filme La sociologie est un sport de combat (A sociologia é um esporte de combate) ${ }^{16}$ : "Espero que eu tenha sido o gatilho de alguma coisa [...] Por que concluir de uma maneira muito pessimista e náo ouvir o que ouvi hoje: cabe a nós mudarmos e vou acrescentar coletivamente, cabe a nós nos mobilizarmos".

Este apelo à esperança e à mobilização é frequentemente interpretado pelos estudantes do ponto de vista prático e revela-se muito eficaz. Os alunos pegam a palavra hostilidade e a desconfiança que começaram a ganhar na aula, e desaparecem rapidamente. No entanto, o significado político do discurso raramente é percebido, sendo mais uma leitura individual do que os alunos estão dizendo.

Ele acha que, quando entendemos tudo isso, nos fará reagir? (Sara, Último ano da ES).

Temos que trabalhar muito mais do que os outros, de fato, senhor! (Lahouari, Último ano da ES).

Dessa forma, quando vemos todos esses números, isso deve nos motivar a sair e ter sucesso. (Withney, Último ano da ES).

Eu não saberei dizer o quanto este momento é realmente performativo no médio prazo (os estudantes realmente trabalharáo muito mais?). Mas, no curto prazo, ele permite encontrar a paz escolar na sala de aula, mantida pela esperança de que tudo seja ainda é possível.

De um ponto de vista pessoal, às vezes é difícil colocar-se claramente em relação a essa leitura filosófica sobre as virtudes da objetivação do determinismo social, tanto as dificuldades escolares persistam e quanto é

16 Pierre Carles. La sociologie est un sport de combat ( $A$ sociologia é um esporte de combate), C-P Production, $200 I$. 
o longo tempo que conta. No final, o tempo de aula pode muitas vezes parecer irrisório na escala dos destinos sociais.

Então, nesses momentos de dúvida, gosto de lembrar a famosa frase de Francis Scott Fitzgerald: "Deve-se, por exemplo, poder entender que as coisas são sem esperança e, ainda assim, decidir mudá-las". ${ }^{17}$

\section{Faça as estatísticas mentirem: "yes, you can”}

A segunda resposta para o problema posto é muito mais pragmática: por trás das estatísticas, se escondem os indivíduos. Se 48,5\% dos graduados das grandes escolas $^{18}$ são filhos de quadros e profissóes intelectuais superiores, 6,4\% são filhos de trabalhadores (CHAUVEL, 2001), os destinos sociais, portanto, não são selados: sair de sua condição original não é impossível, mas é estatisticamente pouco frequente. Trata-se, então, de individualizar o discurso e recorrer a uma retórica mais anglo-saxônica centrada na possibilidade de cada aluno realizar o improvável. Trata-se aqui de abandonar o mito republicano do ideal coletivo meritocrático e a lógica bourdieusiana para juntos pegarmos emprestado do "self made man" o sucesso individual e o ser talentoso.

Esta segunda chamada à ação é em geral ainda mais bem percebida pelos alunos, provavelmente porque é dirigida a cada um ao invés de a todos, desperta em cada aluno o sentimento de que ele será diferente dos outros e que ele poderá fazer melhor. Isso dá, a cada um, a esperança tênue para fazer parte da exceção e não da norma, do acidente e não da média.

Você verá, senhor, o que eu me tornarei. Você ficará surpreso! (Massinissa, Último ano da ES).

Eu quero absolutamente fazer essa escola particular porque eu sei que, afinal, será mais fácil para mim e que eu terei um bom emprego, que pague bem. (Farid, Último ano da ES).

Você terá que manter meus contatos, senhor, porque eu vou ter sucesso e eu vou ser rico. Eu poderei talvez ajudá-lo algum dia! Lembre meu nome! (Ikhlef, Último ano da ES).

17 Francis Scott Fitzgerald. La fêlure, Gallimard, 1945.

180 termo refere-se aqui aos estabelecimentos de ensino superior altamente seletivos que recrutam seus estudantes por meio de concurso. NT. 
Nós realmente queremos que nosso material seja aceito. Queremos fazer essa preparação, nós! (Will e Julien, Último ano da ES).

Além disso, esse ideal desperta um entusiasmo contagiante: o da infinitude do campo de possibilidades; tanto mais forte que os desejos e a necessidade de expressão e de projeção no futuro dos alunos com os quais trabalhei são extremamente fortes. Eles são regularmente expressos em sala de aula ou nos corredores do liceu, especialmente porque sua imaginação vai muito além do ambiente escolar e que a assertividade passa, por muitos alunos, para a fala e a capacidade de romper o silêncio. Ou quando falar é antes de tudo existir.

Não é mais Francis Scott Fitzgerald, mas sim um refrão de NTM ${ }^{19}$ que melhor ilustram esse impulso de energia e determinação quase cego carregado pelos meus alunos e que, muitas vezes, contaminou o professor: "A Seine Saint-Denis, é baby-bomb; e, se você tem o pedigree, é reconhecido pelo fluxo!"20

\section{O que falar quer dizer}

Se o ensinar, é assim falar para dizer, para enfrentar uma aula para dar-lhe conhecimento e dar sentido a ela, o ensino de Pierre Bourdieu no distrito 93 foi para mim uma experiência de confronto social onde falar poderia se arriscar a... Não ter mais nada a dizer.

O ponto de vista do sociólogo e da teoria da dominação e da reprodução colocam a questão do absurdo e da contradiçáo entre os meios implementados e o objetivo visado por cada um na aula. É o significado que o professor dá ao seu trabalho e seu papel social, e o significado que o aluno dá ao seu trabalho, bem como às expectativas de sucesso trazidas pela família e pela instituição que arrisca se perder na objetificação bourdieusiana. Que tal uma missão inútil para o professor e uma missão impossível para o aluno?

19 Suprême NTM é um grupo francês de hip hop formado em 1989 no departamento de Seine-Saint-Denis. NT.

20 NTM, "Seine Saint-Denis Style" in Suprême NTM, Sony Music, 1998. 
A história da sociologia nos lembra que duas posturas clássicas são possíveis: a do protestante descrita por Max Weber que, diante da insuportável predestinação divina, se lança de cabeça no trabalho e na sua profissão-vocação para encontrar os sinais reconfortantes de sua eleição ou do desvio de Robert K. Merton, que, ao constatar que o fim náo pode estar em conformidade com os meios, terá que mudar o objetivo a alcançar, ou o caminho a ser tomado para alcançá-lo, ou terá de agir pela rotina, sem acreditar no que a sociedade idealiza. E para essas escolhas e ao que poderíamos chamar, para parodiar aqui Max Weber, as "consequências psicológicas da ética bourdieusiana” que a classe e o professor são aqui reenviados.

Além disso, essa experiência também coloca em evidência a dificuldade própria da sociologia, que é a recepção da objetivação de suas práticas e a configuração de seu próprio percurso social. Isto é, no nosso caso, ainda maior para superar, lança luz sobre a existência de uma barreira social e cultural entre o professor e seus alunos para enfatizar a influência que pode ter no processo de reproduçáo social, mesmo que a sala de aula deva ser um lugar de vida e um aprendizado coerente onde um único objetivo comum deve animar todos os protagonistas das interaçóes: entender e ter sucesso. E, no contexto em que ensinei, ocorreu-me que qualquer coisa que pudesse prejudicar a coesão do grupo de classe rapidamente levava a um aumento das dificuldades escolares, porque favorece estratégias para evitar encarar o trabalho.

É, portanto, toda a questão das consequências pedagógicas da "violência simbólica" em ato que leva à apresentação da "violência simbólica" teórica que é então colocada.

Por tudo isso, parece-me que as observaçóes de Pierre Bourdieu, assim como os efeitos da reflexividade que necessariamente envolvem, permitiram a cada vez a instauração de uma nova lucidez comum na sala de aula. Eles participam na difusão do conhecimento compartilhado porque ele foi dito, o que leva a interaçóes inovadoras, perguntas e respostas sem precedentes e uma conivência indescritível entre professor e alunos, que parece talvez pouco àqueles que compartilham que foram decretados derrotados, mas que ainda sabem estar de pé. Afinal, a “[...] sociologia confere uma extraordinária autonomia, especialmente quando não é utilizada como arma 
contra os outros ou como um instrumento de defesa, mas como arma contra si mesmo, instrumento de vigilância” (BOURDIEU, 1987, p. 38).

\section{Referências}

BOURDIEU, P. Les Héritiers. Paris: Editions de Minuit, 1964.

BOUDON, R. L'inégalité des chances. Paris: Armand Colin, 1973.

BOURDIEU, P. La distinction. Paris: Editions de Minuit, 1979.

BOURDIEU, P. Le sens pratique. Paris: Editions de Minuit, 1980.

BOURDIEU, P. Choses dites. Paris: Editions de Minuit, 1987.

CHAUVEL, L. Le retour des classes sociales ?, Revue de l'ofce, n. 79, p. 315-369, 2001.

ESPINOSA, B. [1677]. Éthique. Paris, GF-Flammarion, 1965.

FASSIN, D.; FASSIN, E. (Org.). De la question sociale à la question raciale?. Paris: Editions de la Découverte, 2009.

HOGGART, R. La culture du pauvre. Paris: Editions de Minuit, 1970.

SAYAD, A. L'immigration ou les paradoxes de l'altérité. 2. Les enfants illégitimes. Paris: Éditions Raisons d'agir, 2006.

TRUONG, 2010. Enseigner Pierre Bourdieu dans le 9-3: ce que parler veut dire. Revue SocioLogos, n. 5, [s. p.], 13 abr. 2010. Disponível em: https://journals.openedition.org/sociologos/2446\#bodyftn12. Acesso em: 10 abr. 2019.

\section{To teach Pierre Bourdieu at 9-3: what to speak means to say}

\section{Abstract}

This article addresses the confrontation between Bourdieu's high social theory and a public disarmed to appropriate his views about symbolic domination and social inequality: the lowerclass, immigrant pupils of high schools located in the declining urban periphery of the Greater Paris. Through an intensive sociological field work, I propose an empirical observation of the social reception of Bourdieu's work. It questions the risk of meaningless behavior for both pupils and teachers as Bourdieu's theory is going against the necessary meritocratic grain in the classroom and it explores the subjective meaning of the domination theory for dominated individuals, in between acceptance and denial. This study shows that in the French banlieues, it creates an individual and precarious feeling of self-empowerment.

Keywords: Pierre Bourdieu. Reproduction. Meritocracy. Determinism. Inequality. 